\title{
Gantzer muscles and their applied aspects: an exceptional finding
}

\author{
Alok Saxena ${ }^{1}$, Msc, Kishore Kumar $\underline{\text { Agarwall }}^{1}$, Ms, Vidya Parshuram ${ }^{1}$, Msc, Amal Rani Das ${ }^{1}$, Ms
}

\begin{abstract}
Anatomical variations are typically more common in the extensor compartment of the forearm, but uncommon in the flexor compartment. The presence of such anatomical anomalies is not usually noticed until the normal functions of an individual become hindered, or when these anomalies become a surgical problem. During routine dissection curriculum, we encountered a rare finding of bilateral Gantzer muscles in a cadaver. We describe the relationship between the Gantzer muscle and anterior interosseous nerve syndrome.
\end{abstract}

Keywords: anterior interosseous nerve, anterior interosseous nerve syndrome, compartment syndrome

\section{INTRODUCTION}

The flexor compartment of the forearm comprises the superficial and deep groups of muscles. The former includes the pronator teres, flexor carpi radialis, palmaris longus, flexor digitorum superficialis (FDS) and flexor carpi ulnaris muscles, which originate from the medial epicondyle of the humerus. Deep muscles of the flexor compartment of the forearm include the flexor pollicis longus (FPL), flexor digitorum profundus (FDP) and pronator quadratus muscles. Superficial muscles are typically supplied by the median nerve, with the exception of the flexor carpi ulnaris muscle, which is supplied by the ulnar nerve. Deep muscles such as the FPL and pronator quadratus muscles are innervated by the anterior interosseous nerve (AIN), which is derived from the median nerve at the beginning. Conversely, the FDP muscle has a dual nerve supply, with two lateral digits supplied by the AIN and two medial digits by the ulnar nerve. ${ }^{(1)}$

Gantzer in 1813 described two different anomalous bellies in the deep flexor region of the forearm, inserting into either the FDP or FPL muscles. These bellies were thus named Gantzer muscles (Gms), or occasional heads. ${ }^{(2-5)}$ Presence of the accessory heads of FDP and FPL muscles can be described as incomplete division of the deep layer of the flexor muscles' mass, thus showing atavism. ${ }^{(2)}$ Detection of such muscular variations and anomalies has become less tedious due to imaging techniques like magnetic resonance imaging and computed tomography. ${ }^{(6)}$ Flexor and pronator muscles of the antebrachium are mesodermal in origin. Somatic mesoderm invades limb sprouts during the fourth week of embryonic life, forming ventral and dorsal condensation. This ventral condensation forms the flexor and pronator muscles of the upper limb. ${ }^{(7)}$ Four characteristics (with regard to volume and shape) of Gms have been examined in the literature and described as slender, voluminous, triangular and fusiform..$^{(2,7)}$

\section{CASE REPORT}

During routine dissection of a formalin-fixed cadaver (according to instructions in Cunningham's manual of practical anatomy), ${ }_{,}^{(8)}$

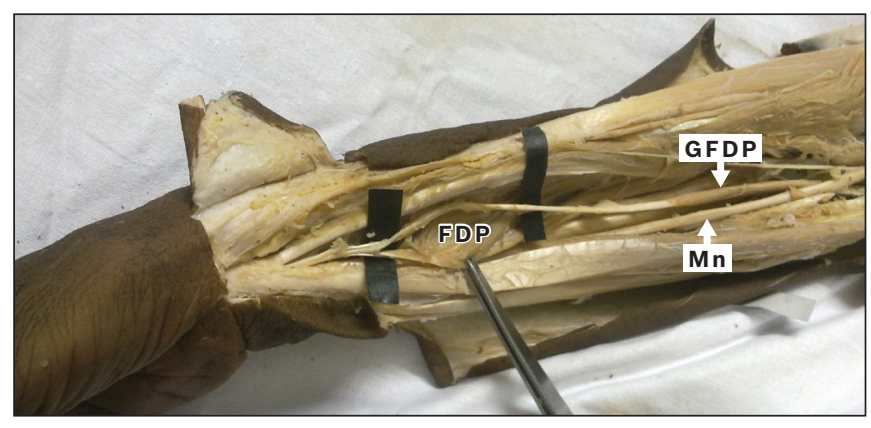

Fig. 1 Photograph shows the dissected flexor compartment of the right forearm, with the Gantzer muscle attached to the flexor digitorum profundus tendon (GFDP), crossed by the median nerve (Mn). Note the insertion of the Gantzer muscle into the flexor digitorum profundus (FDP) tendon and the index finger.

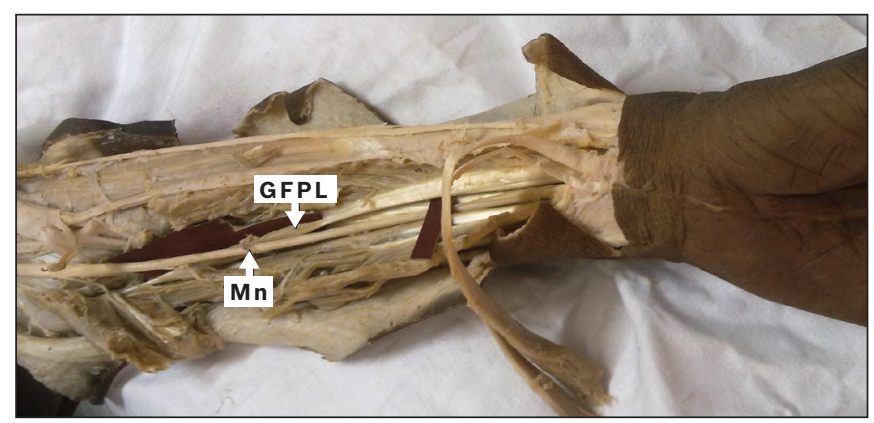

Fig. 2 Photograph shows the dissected left forearm, confirming the tendinous origin of the Gantzer muscle attached to the flexor poliicis longus tendon (GFPL), and the insertion of GFPL. The median nerve (Mn) was found to be superficially related to the GFPL.

we came across two supernumerary muscles in the flexor compartment of the right and left forearms. A fusiform Gm attached to the FDP tendon (GFDP) was observed in the deep flexor compartment of the right forearm, arising from the common flexor origin, under cover of the FDS muscle, and inserting into the first tendon of the FDP muscle (Fig. 1). Another fusiform Gm attached to the FPL tendon (GFPL), a new finding, was found to arise from the left medial epicondyle, ending up in the tendon of FPL in the distal forearm (Fig. 2). Both aberrant slips were crossed

${ }^{1}$ Department of Anatomy, Veer Chandra Singh Garhwali Government Medical Science and Research Institute, Uttarakhand, India

Correspondence: Mr Alok Saxena, Senior Resident, Veer Chandra Singh Garhwali Government Medical Science and Research Institute, Srinagar 246174 , Uttarakhand, India. alok.sxna@gmail.com 
Table I. Comparison of muscle dimensions.

\begin{tabular}{|c|c|c|c|c|c|c|c|c|}
\hline \multirow[t]{2}{*}{ Sources } & \multicolumn{4}{|c|}{ GFDP (cm) } & \multicolumn{4}{|c|}{ GFDP (cm) } \\
\hline & ML & TL & TOL & $\mathbf{w}$ & ML & TL & TOL & $\mathbf{w}$ \\
\hline Jones et al(2) & - & - & - & - & 6.8 & 11.7 & 18.5 & - \\
\hline Vollala et al|(3) & 7 & 15 & 22 & 0.3 & - & - & - & - \\
\hline Campos et al ${ }^{(4)}$ & - & - & - & - & 9.5 & 2.5 & 12 & 0.8 \\
\hline \multirow[t]{2}{*}{ Gorantla et al(5) } & - & - & - & - & 5.9 & 3.25 & 9.10 & 0.6 \\
\hline & 7.2 & 16.7 & 23.9 & 0.8 & - & - & - & - \\
\hline Nayak et al(6) & - & - & - & - & - & - & 7.4 & 0.9 \\
\hline Nayak et al ${ }^{(12)}$ & 5.5 & 9.7 & 15.2 & 0.3 & - & - & - & - \\
\hline Present case & 6 & 11 & 17 & 0.8 & 8.5 & $3^{*} ; 12^{+}$ & 23.5 & 0.4 \\
\hline
\end{tabular}

*Data refers to the tendon of origin. ${ }^{\dagger}$ Data refers to the tendon of insertion.

GFDP: Gantzer muscle of the flexor digitorum profundus muscle; GFPL: Gantzer muscle of the flexor pollicis longus muscle; ML: muscle length; TL: tendon length; TOL: total length; W: width

by the median nerve and innervated by the AIN. Morphometric results of the bilateral Gms in the cadaver, including muscle, tendon and total lengths, and the corresponding widths, were recorded and tabulated together with findings from other reports in the literature (Table I). Photographic documentation of the anatomical variations was also done.

\section{DISCUSSION}

The origin of GFDP has been defined by Wood, ${ }^{(9)}$ Macalister ${ }^{(10)}$ and Le Double ${ }^{(11)}$ to be either the deep surface of the FDS muscle or coronoid process, or a combination of both. Jones et al's study, which supports the findings of the present report, also included other sources of origin of GFDP, like the medial epicondyle and pronator teres muscle, and observed the insertion point in the tendon to the index, middle and little fingers. ${ }^{(2)}$ Nayak et $\mathrm{al}^{(12)}$ and Vollala et $\mathrm{al}^{\left({ }^{(3)}\right.}$ also showed similar results in terms of the origin of GFDP, observing its insertion in the FDP tendon to the middle finger. In our present report, we found that GFDP originated from the right medial epicondyle, which inserted into the FDP tendon and then to the index finger.

According to the literature, the occurrence of bilateral GFPL is more prevalent than that of GFDP. ${ }^{(13)}$ This abnormal muscle is found in more than $50 \%$ of individuals worldwide. ${ }^{(13)}$ Earlier reports suggest that GFPL originates from under the surface of the FDS muscle and inserts into the ulnar side of the FPL muscle. ${ }^{(4-6)}$ Our present case also reports similar results regarding the origin and insertion of GFPL unilaterally. In the present case, morphometric analyses of the GFDP and GFPL were done and their results are compared with previous studies in Table I. Based on clinical studies, the presence of Gm could be a cause of paralysis of the AIN. Compression of this nerve in the forearm, known as Kiloh-Nevin syndrome, is characterised by flexion deformity of the interphalangeal joint of the thumb and distal interphalangeal joint of the index finger (Spinner's sign). Differential diagnosis of flexion deformities in the hand can be made based on the following: (a) congenital absence of deep flexor muscles; (b) rupture of flexor tendons in rheumatoid diseases; (c) Kienbock's disease; and (d) injury to the medial root of the median nerve. ${ }^{(14,15)}$ The presence of an aberrant muscle tendon in the forearm and wrist may be a causative factor of carpal tunnel syndrome. ${ }^{(16)}$ These Gms may lead to restricted hand movements, characterised by burning pain in the distal forearm via a muscle-tendon shearing action. . $^{(3)}$

The finding of the long tendon of the GFDP in the present report has significant influence, as this tendon helps to enhance the power of the index finger. This tendon can be utilised in tendon repair surgeries in order to improve lost hand function. The presence of GFDP and GFPL in the anterior compartment of the forearm may result in painful compartment syndrome due to a decreased availability of space. Our present case reports a rare finding of bilateral Gms and their potentially hazardous effects on the AIN. This report may thus provide radiologists and surgeons with relevant information necessary for differential diagnosis of AIN syndrome.

\section{REFERENCES}

1. Johnson D. Pectoral Girdle and Upper Limb. In: Standring S, Borley NR, Collins P, et al, eds. Gray's Anatomy: The Anatomical Basis of Clinical Practice. 40th ed. Edinburgh: Churchill Livingstone, 2008: 845-7.

2. Jones M, Abrahams PH, Sa-udo JR, Campillo M. Incidence and morphology of accessory heads of flexor pollicis longus and flexor digitorum profundus (Gantzer's muscles). J Anat 1997; 191:451-5.

3. Vollala VR, Nagabhooshana S, Bhat SM, Potu BK, Rakesh V. Multiple accessory structures in the upper limb of a single cadaver. Singapore Med 2008; 49:e254-8

4. Campos D, Nazer MB, Bartholdy LM. Anatomical variation of the accessory muscle of the forearm (Gantzer's muscles) and his relationship with the median nerve: a case report in human. J Morphol Sci 2009; 26:39-41.

5. Gorantla VR, Potu BK, Jetti R, Vollala VR, Pulakunta T. Rare origin of two accessory bellies from the undersurface of the flexor digitorum superficialis muscle. Eur J Gen Med 2009; 6:57-9.

6. Nayak SR, Ramanathan L, Prabhu LV, Raju S. Additional flexor muscles of the forearm: case report and clinical significance. Singapore Med J 2007; 48:e231-3.

7. El Domiaty MA, Zoair MM, Sheta AA. The prevalence of accessory heads of the flexor pollicis longus and the flexor digitorum profundus muscles in Egyptians and their relations to the median and anterior interosseous nerves. Folia Morphol (Warsz) 2008; 67:63-71.

8. Romanes GJ. Upper and lower limbs. In: Cunningham DJ, Romanes GJ. Cunningham's Manual of Practical Anatomy. 15th ed, Vol 1. New York: Oxford University Press, 1993: 67-8, 74-6.

9. Wood J. Variations in human mycology observed during the winter session of 1867-68 at King's College, London. Proc R Soc Lond 1867; $16: 483-525$. 
10. Macalister A. Additional observations on muscular anomalies in human anatomy (3rd series), with the catalogue of principal muscular variation hitherto published. Trans R Ir Acad 1875; 25:1-130.

11. Le Double AF. Traité des variations du système musculaire de l'homme et de leur signification au point de vue de l'anthropologie zoologique. Vol 2. Paris: Schleicher Frères, 1897: 99-107. French.

12. Nayak SR, Krishnamurthy A, Ramanathan LA, et al. Multiple muscular anomalies of upper extremity: a cadaveric study. Rom J Morphol Embryo 2008; 49:411-5

13. Potu BK, Gorantla VR, Pulakunta T, et al. Accessory head of flexor pollicis longus muscle and its significance in anterior interosseous nerve syndrome: case report and review. Int J Morphol 2007; 25:911-4.

14. Gardner-Thorpe C. Anterior interosseous nerve palsy: spontaneous recovery in two patients. J Neurol Neurosurg Psychiatry 1974; 37:1146-50. 15. Degreef I, De Smet L. Anterior interosseous nerve paralysis due to Gantzer's muscle. Acta Orthop Belg 2004; 70:482-4.

16. Rodrigues $\mathrm{V}$, Nayak SB, Rao MK, et al. Abnormal muscle in the anterior compartment of the forearm: a case report. Cases J [serial online] 2009; 2:9125. Available at http://www.casesjournal.com/content/2/19125. Accessed August 28, 2011. 